\title{
Implementation of Police Patrols Based on an Intelligent Model of VRP
}

\author{
María B. Bernábe ${ }^{1}$, Alberto Ochoa Zezzatti ${ }^{2}$, Rogelio González ${ }^{1}$, \\ Jorge Ruiz Vanoye ${ }^{3}$, Martín Estrada Analco ${ }^{1}$ \\ ${ }^{1}$ Benemérita Universidad Autónoma de Puebla, \\ Facultad de Ciencias de la Computación, Mexico \\ ${ }^{2}$ Universidad Autónoma de Ciudad Juárez, \\ Maestría en Cómputo Aplicado, Mexico \\ ${ }^{3}$ Universidad Autónoma del Estado de Hidalgo, Mexico \\ \{rgonzalez, mestrada\} @cs.buap.mx, \\ beatriz.bernabe@gmail.com, alberto.ochoa@uacj.mx
}

\begin{abstract}
In this paper we present the implementation of police patrols based on an intelligent model of VRP using an algorithm of variable neighborhood search, which allows to solve vehicle routing situations, obtaining results that show optimization, problems arising from transportation, distribution and logistics; in most markets, transport means a value added to goods, for which the use of computerized methods of transportation resulting in significant savings. Most optimization problems of the real world are dynamic, that is, because the information available about the situation you want to solve is variable over time. One example is the problem of routing of dynamic order in which is required to develop a service plan for a set of clients using a fleet of vehicles, in order to include in the plan to new customers who send their orders along the route or the workday. We use MATLAB for algorithm development, data visualization, and numeric computation. With ant colony algorithm to calculate the total time of the patrols.
\end{abstract}

Keywords. Police patrols, dynamic optimization, variable neighborhood search algorithm, vehicle routing problems, Matlab.

\section{Introduction}

The VRP constitutes a series of problems that can be formulated mathematically by means of directed graphs, otherwise the VRP is a method that aims to optimize the resources for the production of any type of product to the consumer or customer and services. 
Today, technology tools can be used for troubleshooting using simulation systems or software, these systems are based on mathematical algorithms in a way users of these systems develop their logic [5,7].

Therefore, most optimization problems are dynamic, that is, form the information changes over time. In these cases, the algorithms that are able to adapt to a changing environment can provide greater results than a search reset after each change. An optimization problem in the real world of great interest is the vehicle routing problem (VRP). Described for the first time in [3], with applications in the field of transport and telecommunications. One goal of this problem is to reduce the cost of the routes taken by a fleet of vehicles to service the requests of a number of customers.

Currently, is possible to run a fleet of vehicles in real time, thanks largely to advances in the field of ICT, such as the use of sensors to measure traffic flow, global positioning systems, or GPS to determine the exact position of the vehicles in case of theft or to monitor execution paths for each car, mobile communication systems to provide real-time information, etc. In this content, you can define characteristics involving dynamic information in the classical VRP, namely, problems such as the shortest path between two clients can be blocked by an accident or because weather or also that customers change the routes of their orders, etc. Considering the above explained, the dynamic VRP are a number of different problems, very important in the industry and that they can carry out a study to improve efficiency in distribution systems [2,7].

The goal of most basic VRP is to deliver and collect goods for a set of customers with known demands, with minimal cost, finding optimal routes that begin and end in a reservoir where each client is visited once and the vehicles carrying load.

To make this work we consulted articles in PDF for VRP or GVRP, book, manual, examples and demos of Matlab, as well as the book design of experiments Roman Vaez and VRP thesis, paper related to the topic.

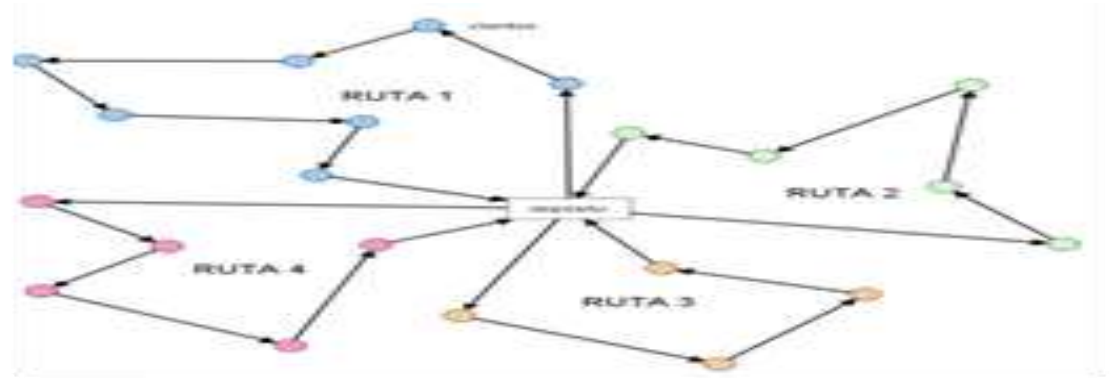

Fig. 1. Generic representation of a VRP Fuente [7].

A route is a simple cycle containing an origin and a destination and represents the sequence of visits made by a vehicle traveling the route, the cost and time of a route is obtained by adding the costs and times of the arcs that form the cycle. 


\subsection{Features VRP}

According to [5] the main features of VRP are: The network transport is considered a terrestrial network, but can also be considered an airline or shipping network or a combination of both to problems that are seen in other types of transport. Customers: are characterized by a demand that must be satisfied by a vehicle and in many cases demand are assets that have a place in the vehicle. Deposits: vehicles are those that are responsible for distributing the goods for which should be directed to deposits and routes begin and end in the same tank. Routes: the objective is to minimize fixed and total costs, the number of vehicles per route, transportation time and distance as well as the benefits and customer satisfaction.

\subsection{Types of VRP Problems}

Problems with capacity constraints (PTRC) is a variant of VRP in which a fleet of vehicles to serve a number of clients from a tank at minimal cost, your goal is to minimize the fleet, the sum of the time routes and total demand for each customer.

Problems with time windows (VRPTM) are the same problem as the VRP with the difference that is required to serve customers in a given period of time. Its aim is to minimize the fleet, the amount of travel time and waiting time.

Problem with multiple deposits (MDVRP): when a company has several stores where you can serve your customers, if customers are around the deposits, the distribution may be modeled by a group of VRP's, however, if customers and the deposits are mixed, is different and its modeling is performed through a MDVRP.

Problems with delivery and returns (VRPPD) is a variant of VRP where a customer who has received a sent also have some merchandise that needs to be gathered by which it should be aware that products that customers sent must not exceed the vehicle capacity, this need hinders the problem of planning and exceeds the capacity of the vehicles, the distances or increases the need for a larger vehicle.

Problem of partial deliveries (SDVRP) is an advantage of generic VRP problem because it allows the same client to be visited by various delivery vehicles. This advantage is important if the size of the customer demand is as great as the capacity of the vehicles.

Random value problem (SVRP) is performed in two stages to reach a solution. The first is to determine before knowing the value of the variables and the second corrective action is taken when the values of the variables are known.

Periodic problem VRP (PVRP) is planning an extension of $\mathrm{N}$ days, your goal is to minimize the fleet and the total time of transport to serve all customers. During the course of $\mathrm{N}$ days each client must be visited at least once [7].

Matlab is an abbreviation of MATrix LABoratory because it supports vector and matrix operations that are fundamental to the solution of engineering problems and science, whatever with tools called toolboxes that extend graphical environment capacity to solve specific problems in specific areas.

MATLAB is a computer language that allows you to perform operations and faster than other languages like $\mathrm{C}, \mathrm{C}++$ and FORTRAN computational tasks. The tasks are 
the development of algorithms, data visualization and numerical computations and can be used in applications such as signal analysis and imaging, communications, control, test and measurement, analysis, financial modeling and computational biology [1].

\subsection{Description of Nearest Neighbor Algorithm}

The main idea of the algorithm of the nearest neighbor method is to make a number of copies of their behavior over time, namely, that the information on the latest series match the latest information available before observation $t+1$.

The purpose of Nearest Neighbor algorithm is to locate similar pieces of information, regardless of location in time [8].

\subsection{Types of VRP Problems}

Patrol or policing action is set displacement on routes established and controlled, exercising oversight in a given territory. And areas are performed by using a preventive police.

Procedure 1: Algorithm of a local search for the closest neighbor [4]

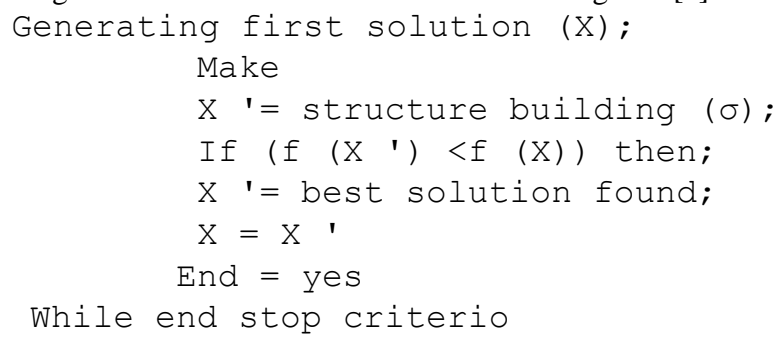

Within the zone or area to watch is: Urban area which consists of industrial area, residential area and commercial area. Surveillance routes for urban area are: neighborhoods, schools, household, temples, parks, flea markets, recreational facilities, etc.

One of the purposes of police patrols is to prevent, stop in fragrance, protect, and encourage citizen participation and support the administration of justice, in coordination with various police forces and government.

To meet the patrols of police is necessary to establish monitoring devices which are operational plans that help fulfill the purposes of police surveillance, operations were performed with the use of equipment and material to be alert [9].

\subsection{The Patrols can be Classified into Five Types [9]}

Stationary patrol: It is performed by an element that is responsible for granting security to a specific place such as: companies, shops, booths modules and security and surveillance which are supported by auto patrols or other mobile. 
Mobile patrol: It is carried out by using a conveyance as may be patrols, bicycles, motorcycles, horses and even takes place on foot, to make the patrol certain areas are crossed with special attention to everything that is out of order.

Mixed patrol: This takes more than just a specific type of monitoring devices usually is the combination of mobile patrol or system closed-circuit monitoring.

Patrol monitored: They are made using instruments or electronic devices and video devices remotely controlled by one or two audio items.

With the use of technology, we can make a satellite patrol [9]: It is done through GPS or global positioning systems that allow us to find the exact location of a mobile anywhere in the world.

\section{Methodology}

MATLAB program for the nearest neighbor algorithm determines the number of patrols and total distance, source [11].

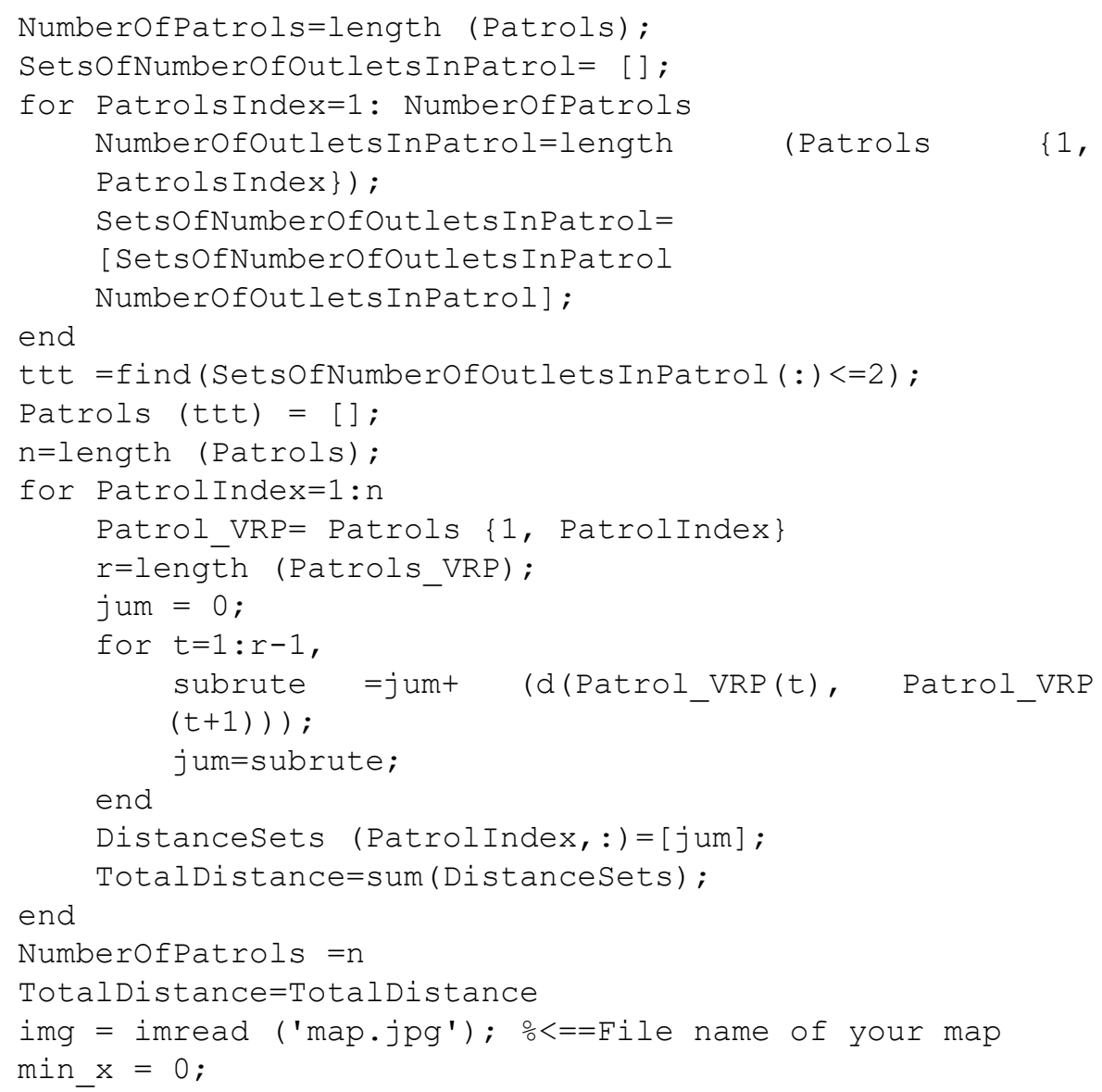




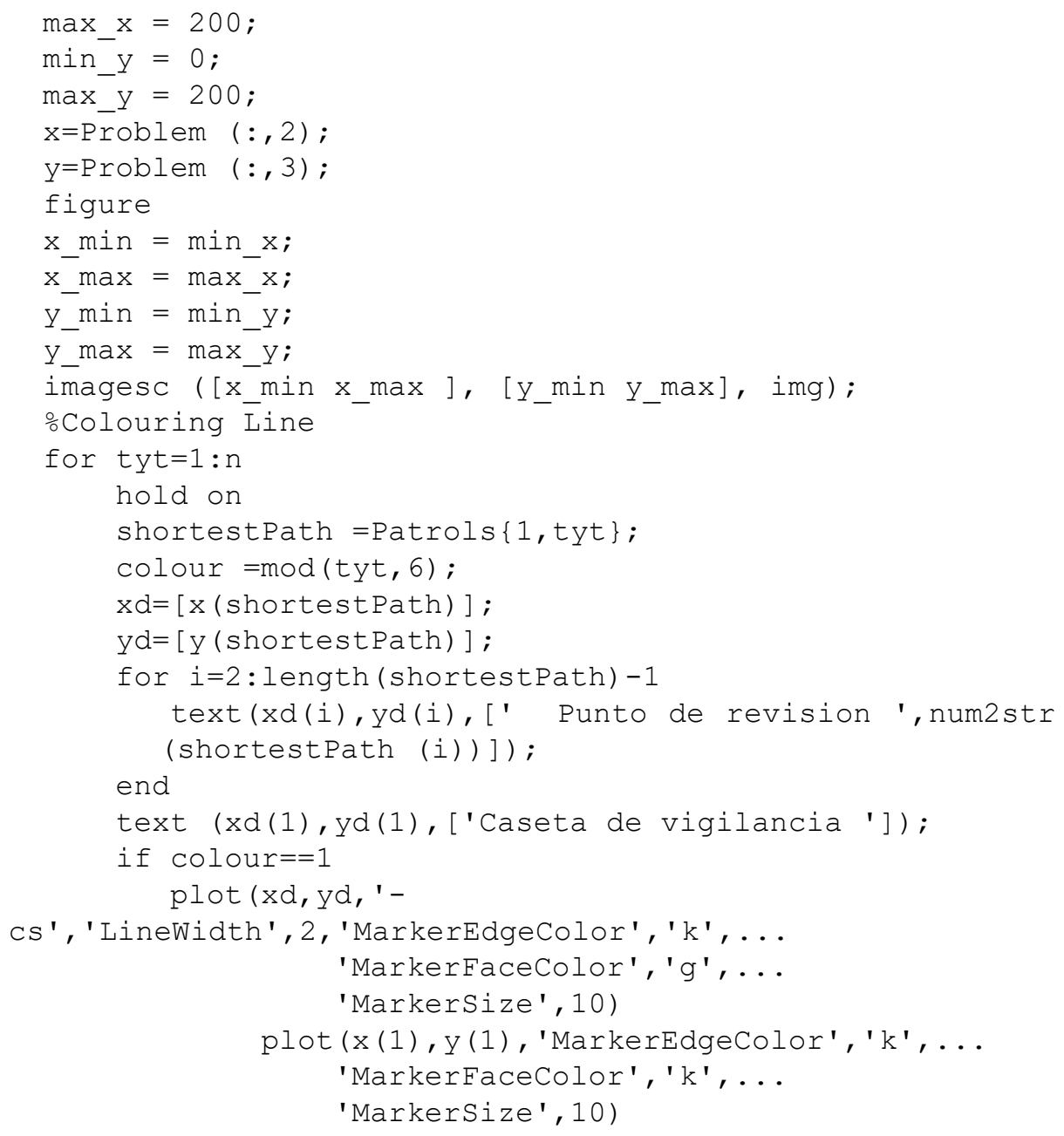

Table 1. Results of the execution of the request.

\begin{tabular}{ll}
\hline Police patrol & Points instance \\
\hline Patrol_1_VRP & $5,14,9,10,2$ \\
Patrol_2_VRP & $7,4,11,15,24,23$ \\
Patrol___VRP & $22,13,21,12,3$ \\
Patrol_4_VRP & $8,20,6.19$ \\
Patrol_5_VRP & $18,17,16,25$ \\
& \\
Number a police & \\
patrol & 5 \\
Distance total & 623.3026 \\
&
\end{tabular}




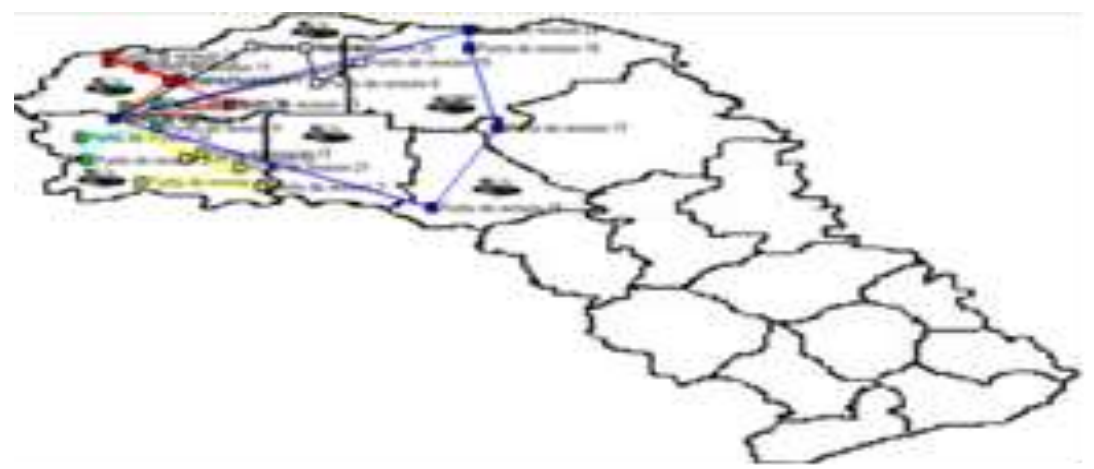

Fig. 2. Map with patrols of Chihuahua capital.

The map shows where population is located and where most criminal activity is located so it is necessary to go more than once for a police patrol.

The population density according to INEGI in 2010 in this capital city of Chihuahua is 14 people per square kilometer.

The test results of the ant colony code show that $60 \%, 80 \%$ and $100 \%$ of allocated vehicles can cover an area of 5 patrols police in a colony, as shown in Figure 4 which correspond to eastern Chihuahua.

$\mathrm{C}++$ program ant colony to determine the total travel time of the patrols. The printing area must be $122 \mathrm{~mm} \times 193 \mathrm{~mm}$. The text is justify for each paragraph.

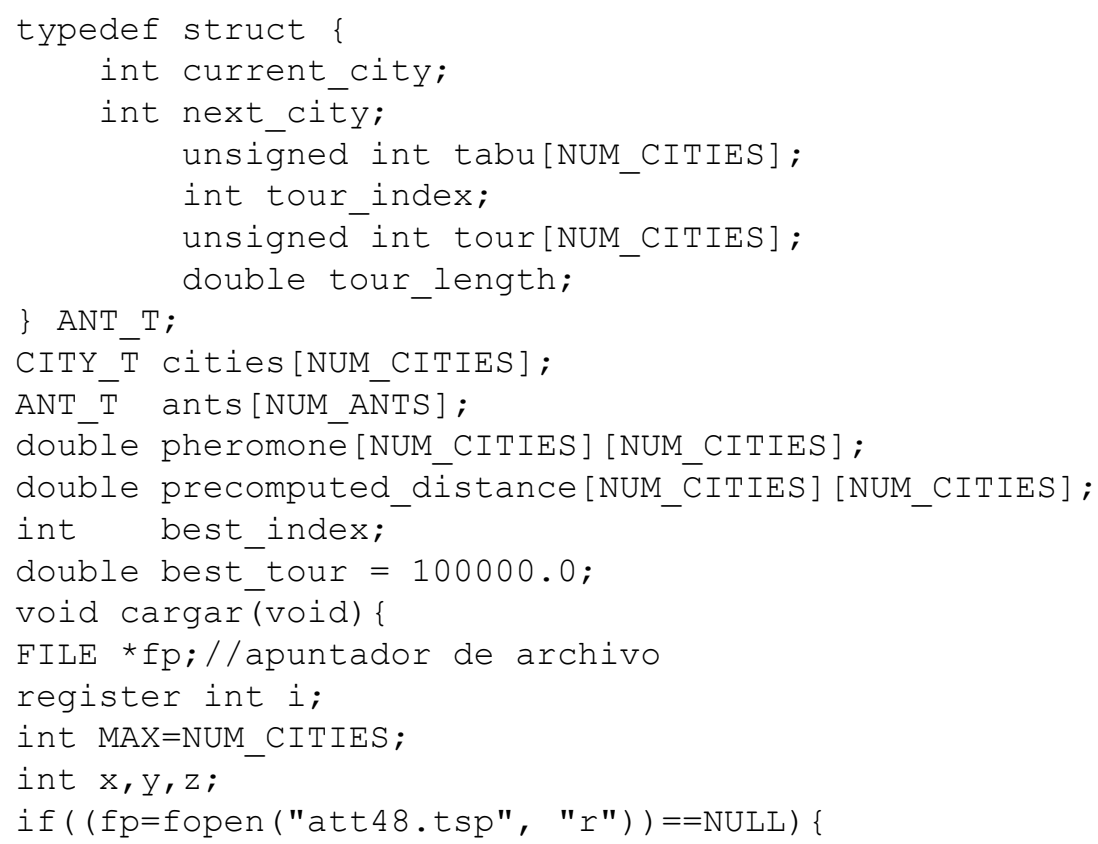


Beatriz Bernábe Loranca, Rogelio González Velazquez, Jorge Alberto Ruiz-Vanoye, et al.

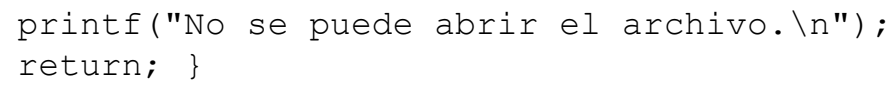

\subsection{Design of Experiments for the Ant Colony Program}
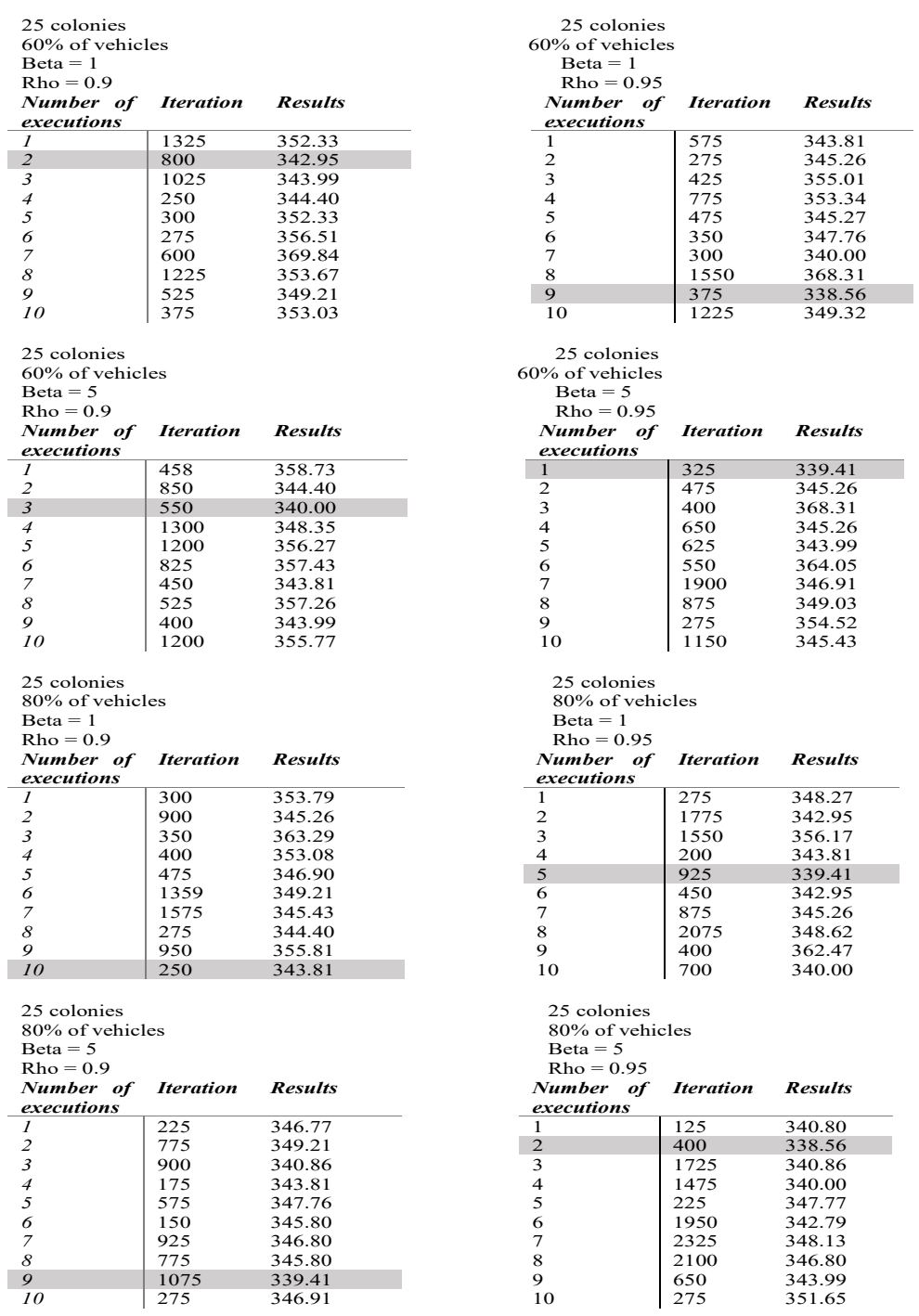

25 colonies

$60 \%$ of vehicle
Beta $=5$

Beta $=5$
Rho $=0.95$

Number of Iteration Results

\begin{tabular}{|l|ll} 
executions & \multicolumn{3}{l}{} \\
\hline 1 & 325 & 339.41 \\
2 & 475 & 345.26 \\
3 & 400 & 368.31 \\
\hline
\end{tabular}

\begin{tabular}{l|ll}
3 & 400 & 368.31 \\
4 & 650 & 345.26 \\
5 & 625 & 343.99 \\
6 & 550 & 364.05
\end{tabular}

\begin{tabular}{l|ll}
6 & 550 & 364.05 \\
7 & 1900 & 346.91
\end{tabular}

\begin{tabular}{l|ll}
8 & 875 & 349.03 \\
9 & 275 & 354.52 \\
10 & 1150 & 345.43
\end{tabular}

25 colonies

$80 \%$ of vehicles

Beta $=1$

Number of Iteration Results

Number of Iteration Results
executions

\begin{tabular}{l|ll} 
executions & \multicolumn{3}{l}{} \\
\hline 1 & 275 & 348.27 \\
2 & 1775 & 342.95 \\
3 & 1550 & 356.17 \\
4 & 200 & 343.81 \\
5 & 925 & 339.41 \\
6 & 450 & 342.95 \\
7 & 875 & 345.26 \\
8 & 2075 & 348.62 \\
9 & 400 & 362.47 \\
10 & 700 & 340.00
\end{tabular}

25 colonies

25 colonies
$80 \%$ of vehicles

$\mathrm{Beta}=5$
$\mathrm{Rho}=0.95$

\begin{tabular}{l|ll}
$\begin{array}{l}\text { Rho } \begin{array}{l}\text { Rumber of } \\
\text { executions }\end{array} \\
\text { exeration }\end{array}$ & Results \\
\hline 1 & 125 & 340.80 \\
2 & 400 & 338.56 \\
3 & 1725 & 340.86 \\
4 & 2275 & 340.00 \\
5 & 1950 & 347.77 \\
6 & 2325 & 342.79 \\
7 & 2100 & 348.13 \\
8 & 650 & 343.80 \\
9 & 275 & 351.69 \\
10 & &
\end{tabular}




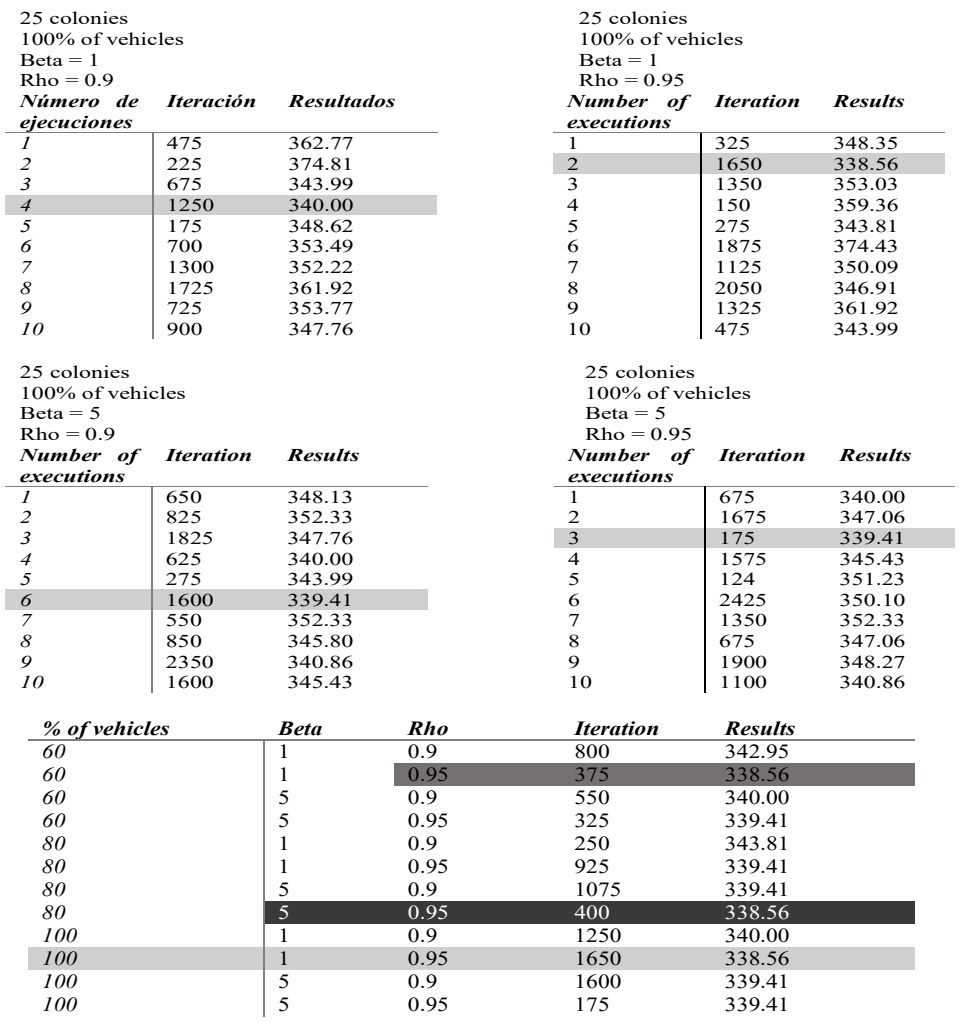

Table 2. Results of experimental design.

\begin{tabular}{cclc}
\hline \% of vehicles & Beta & Rho & Iteration \\
\hline 60 & 1 & 0.9 & 800 \\
60 & 1 & 0.95 & 375 \\
60 & 5 & 0.9 & 550 \\
60 & 5 & 0.95 & 325 \\
80 & 1 & 0.9 & 250 \\
80 & 1 & 0.95 & 925 \\
80 & 5 & 0.9 & 1075 \\
80 & 5 & 0.95 & 400 \\
100 & 1 & 0.9 & 1250 \\
100 & 1 & 0.95 & 1650 \\
100 & 5 & 0.9 & 1600 \\
100 & 5 & 0.95 & 175 \\
\hline
\end{tabular}

The first column shows the percentage of ants.

Vehicle of $60 \%=15$.

Vehicle of $80 \%=20$.

Vehicle of $100 \%=25$. 
These results were obtained with $60 \%, 80 \%$ and $100 \%$ of the assigned vehicles can cover 5 patrols, a colony.

Based on the results shown in the table it was obtained that the best values for beta, and rho is the percentage of vehicles:

Beta $=1$.

Rho $=0.95$.

$\%$ Vehicles $=100 \%$

In order to be able similar, the most efficient arrangement of individuals in a social network, we developed an atmosphere able to store the data of each one of the representing individuals of each society, this with the purpose of distributing of an optimal form to each one of the evaluated societies. One of the most interesting characteristics observed in this experiment was the diversity of the cultural patterns established by each community. The scenes structured associated with the agents cannot be reproduced in general, since they only represent a little while dice in the space and time of the different societies. These represent a unique form and innovating of adaptive behavior which solves a computational problem that it does not try to clustering the societies only with a factor associated with his external appearance (attributes of each society), trying to solve a computational problem that involves a complex change between the existing relations. The generated configurations can be metaphorically related to the knowledge of the behavior of the community with respect to an optimization problem (to select culturally 47 similar societies, without being of the same quadrant [3]).

Table 3. Orthogonal array.

\begin{tabular}{|c|c|c|c|c|c|c|c|c|}
\hline \multicolumn{9}{|c|}{ Variable Value } \\
\hline A & B & C & $\mathbf{D}$ & $\mathbf{E}$ & $\mathbf{F}$ & $\mathbf{G}$ & $\mathbf{H}$ & Color \\
\hline H & $H$ & $\mathrm{H}$ & $\mathrm{H}$ & $H$ & $H$ & $\mathrm{H}$ & L & 1 \\
\hline $\mathrm{H}$ & $\mathrm{H}$ & $\mathrm{H}$ & $\mathrm{H}$ & $\mathrm{H}$ & $\mathrm{H}$ & $\mathrm{L}$ & $\mathrm{H}$ & 2 \\
\hline $\mathrm{H}$ & $\mathrm{H}$ & $\mathrm{H}$ & $\mathrm{H}$ & $H$ & L & $\mathrm{H}$ & $\mathrm{H}$ & 3 \\
\hline $\mathrm{H}$ & $\mathrm{H}$ & $\mathrm{H}$ & $\mathrm{H}$ & $\mathrm{L}$ & $\mathrm{H}$ & $\mathrm{H}$ & $\mathrm{H}$ & 3 \\
\hline$=$ & - & $\ldots$ & $=$ & $\ldots$ & - & $\ldots$ & $\ldots$ & $=$ \\
\hline
\end{tabular}

The main experiment consisted of detailing each one of the 1087 communities, with 500 agents, and one condition of unemployment of 50 époques, this allowed us to generate the best selection of each Quadrant and their possible location in a Diorama, which was obtained after comparing the different cultural and social similarities from each community, and to evaluate with Multiple Matching Model each one of them [10]. The developed tool classified each one of the societies pertaining to each quadrant, with different wardrobe for societies that included linguistic identity and for societies only with cultural identity; this permit identifies changes in the time respect at other societies. 
The design of the experiment consists in an orthogonal array test, with the interactions between the variables: emotional control, ability to fight, intelligence, agility, force, resistance, social leadership, and speed. These variables are studied in a range of color (1 to 64).

The orthogonal array is $\mathrm{L}-\mathrm{N}(2 * * 8)$, in other words, 8 factors in $\mathrm{N}$ executions, $\mathrm{N}$ is defined by the combination of possible values of the 8 variables an the possible range of color (To see Table 1).

\section{Conclusions and Future Work}

In this paper the different VRP problems were analyzed and using the nearest neighbor algorithm map with police patrols which shows what will be the patrol largest number of routes are generated.

Using ant colony algorithm principle to understand its operation and analyzing the structure of the code for operation at program execution. It is concluded that $60 \%$, $80 \%$ and $100 \%$ of vehicles can cover a land area of 5 patrols.

Future work of this research is the implementation of algorithms for solving such problems route, aimed at companies to improve their product delivery logistics, to improve service quality, timely delivery and satisfaction of clients.

\section{References}

1. Báez, D. et al.: MATLAB Con Aplicaciones a la Ingeniería, Física y Finanzas. 2a edición, 4-287 (2016)

2. Carrasco, R. et al.: TIC para una logística más sostenible (2015)

3. Dantzig G. B. and Ramser J. H.: The truck dispatching Problem. Operations Research Management Sciences, 6(1), 80-91 (1959)

4. Bentz, J.L., Kozak, J.J.: Influence of geometry on light harvesting in dendrimeric systems. II. Nth-nearest neighbor effects and the onset of percolation. Journal of luminescence, 62-74 (2006)

5. Ponce. J. et al.: Algoritmo de colonia de hormigas en CUDA para la optimización de rutas de distribución. Komputer Sapiens by Published

6. Rodas, J. et al.: Use of GVRP as a model of two specific real world problems and its bioinspired solution. Chapter by published. The book, Handbook of Research on Military, Aeronautical, and Maritime Logistics and Operations

7. Rodríguez, J.: Caracterización, Modelado y Determinación de las Rutas de la Flota en una Empresa de Rendering e-reading by Published

8. Sarasola, B. et al.: Un algoritmo de búsqueda en vecindario variable para la asignación de rutas a vehículos con pedidos dinámicos. SIMD by Published.

9. Técnicas de la intervención policial, programa de homologación en formación inicial para policías municipales

10. Inegi: Nombre de la página www.cuentame.inegi.org.mx. Densidad de población en Chihuahua capital. Consulted 2017

11. WahidS.H. Mathworks. Home page http://www.mathworks.com/matlabcentral/news reader/view_thread/324824. Programa en Matlab del vecino más cercano. Consulted 2015 